\title{
Advanced and metastatic renal cell carcinoma - Ain Shams Clinical Oncology Department Experience
}

\author{
Ahmed Nagy, Mona Kamal, Hesham El Halawani \\ Department of Clinical Oncology, Ain Shams University, Cairo, Egypt
}

Received: May 9, 2019

Accepted: December 20, 2019 Online Published: February 19, 2020

DOI: $10.5430 /$ jst.v10n1p18

URL: https://doi.org/10.5430/jst.v10n1p18

\begin{abstract}
Background: Renal cell carcinoma is a rare tumor and till recently few treatment options were available. It is poorly understood why people develop RCC since only a few etiologic factors have been clinically identified as risk factors for RCC.

Purpose: To analyze our experience at Ain Shams University Clinical Oncology department in Egypt with patients presenting with advanced renal cell carcinoma to provide a correlations between clinic-pathological factors, treatment and survival outcomes. Methodology: Retrospective review of the data of 54 patients who were diagnosed as RCC and presented to Ain Shams University Clinical Oncology department in Egypt from 1 May 2013 till 1 May 2015. Descriptive and clinic-pathological data were described using simple and relative frequencies. Survival outcome for the patients will be described using Kaplan Meier curves stratified according to morphology, age group and treatment received.

Results: The sample included 54 patients (53.7\% were males) of whom $14.3 \%$ were less than 40 years and $3.7 \%$ were elderly ( $\geq 70$ years old). The median age was 55.5 years $(\mathrm{SD} \pm 13.6$, range 19-71). Median PFS was 6.5 months ( $\mathrm{SD} \pm 12.3846$ Range 43) while the median OS was 13 months (SD \pm 12.161 Range 46). PFS in patients aged below 55.5 years was 9 months (95\% CI=6.509-11.491) compared to 4 months $(95 \% \mathrm{CI}=2.704-5.296)$ in older patients $(p=.004)$. PFS in patients who achieved PR after sunitinb was 17 months ( $95 \% \mathrm{CI}=6.916-27.084)$ compared to 5 months (95\% CI=3.699-6.301) in patients who didn't achieved PR $(p<.001)$. OS in patients aged below 55.5 years was 15 months $(95 \% \mathrm{CI}=9.131-20.869)$ compared to 11 months $(95 \% \mathrm{CI}=8.947-13.053)$ in older patients $(p=.012)$. Favorable pathology status was associated with prolonged OS of 14 months (95\% CI= 9.403-18.597) versus 11 months (95\% CI=8.363-13.637) for unfavourable pathology status $(p=.11)$ Low grades histopathogy was associated with prolonged OS of 44 months (95\% CI= 38.456-49.544) versus 12 months (95\% $\mathrm{CI}=10.077-13.923)$ for higher grades $(p=<.001)$.

Conclusion: Multivariate analyses supported a conclusion that younger age was an independent prognostic factor for survival along with other known risk factors such as tumor grade and pathology status.
\end{abstract}

Key Words: RCC, Metastatic, Survival

\footnotetext{
*Correspondence: Ahmed Nagy; Email: ahmedalynagy@yahoo.com; Address: Department of Clinical Oncology, Ain Shams University, Cairo, Egypt.
} 